\title{
Introduction from Our Guest Editors
}

\section{Special issue: Microvariation in the quantificational domain}

\author{
Ellen Brandner • Helmut Weiß
}

Published online: 6 March 2009

(C) Springer Science + Business Media B.V. 2009

The papers in this issue of The Journal of Comparative Germanic Linguistics grew out of a workshop that was held at the annual meeting of the DGfS 2007 (German Society for Linguistics) in Siegen. The organizers were Sjef Barbiers, Ellen Brandner, and Helmut Weiß.

All papers deal with microvariation in a specific syntactic area, namely what we termed the "quantificational domain." This should be taken as a 'broad' cover term for the left periphery of embedded clauses, negation, Tense-Aspect systems, internal structure of DP, etc. So we focused on variation of what could be called 'functional elements.' We started from the observation that standardized (written) languages are known to be rather 'parsimonious' in the overt encoding of functional structure especially in this domain. One of the (probably) best known examples is what is referred to as the 'Doubly filled Comp Filter'. Whereas in the standardized variant the complementizer is absent, many of the dialects of German(ic) insist that it be overtly realized:

(1) a. Ich möchte wissen mit wem du gesprochen hast. Standard German I want know with whom you talked have

b. I mechtet wissen mit wem dass'd gsprochen hast. Bavarian I want-SUBJ know with whom that you talked have

c. I tät gern wüsse mit wem dass du g'schwätzt hesch. Alemannic I do-SUBJPRT know with whom that you talked have

'I want to know who you talked with.'

E. Brandner $(\bowtie)$

Universität Konstanz, Universitätsstr. 10, 78457 Konstanz, Germany

e-mail: eleonore.brandner@uni-konstanz.de

H. Weiß $(\bowtie)$

Institut für kognitive Linguistik, Goethe-Universität Frankfurt am Main, Grüneburgplatz 1, 60629 Frankfurt am Main, Germany

e-mail: weiss@lingua.uni-frankfurt.de 
This is true not only for German (and its dialects) but also holds for Dutch and English. Other examples of this general phenomenon are:

Negative concord:

(2) Es hät neamed nünt gseet.

Alemannic

Expl has nobody nothing said

'Nobody said anything.'

Complementizer agreement:

(3) wennsd pro mogsd

Bavarian

if-2Sg pro like-2Sg

'if you like'

Quantifier accompanied by a determiner:

(4) weil halt a jeder a Auto will

because prt a each a car wants

'because everybody wants to have a car'

Relative clauses with RP + wo/was

(5) Des isch der Maa mit dem wo du telefoniert häsch. this is the man with whom RPRT you phoned have 'This is the man with whom you've phoned.'

Possessive doubling:

(6) am Sepp sei Haus

Bavarian

the-DAT Joe his house

'Joe's house'

These 'doubling' or 'redundant' structures seem to be typical for dialects or other non-standardized languages; see Sjef Barbiers' description of the Edisyn project (http:// www.meertens.knaw.nl/projecten/edisyn/), where similar constructions are illustrated.

If one considers this pattern, there arise several questions:

- What are the common properties - if there are any at all —of these elements?

- In which sense are they 'superfluous' such that standardized languages tend to omit them?

- What can these 'superfluous' realizations tell us about the internal structure of these projections?

- What does this tendency to omission tell us about the language faculty, e.g., what is the role of recoverability via the syntactic surrounding? 
- Are standardized languages then 'incomplete' in a certain sense?

- Or is it rather the case that dialects show a tendency to be redundant?

- Finally, do these phenomena have an impact on the general question concerning economy?

Given that standardized languages obviously can do without a doubly filled Comp or multiple expression of negation within one clause, do the dialects then violate economy of representation? Or is it the other way round? Maybe the current concept of economy does not play the crucial role that is generally assumed. A further follow-up of these considerations might be that the nature of economy is quite different from what has been assumed until now.

It is questions of this sort that have directed the attention in recent generative research to data from dialects. There is one general argument in favour of dialects: they are fully natural languages in a very precise sense. If we define a language's naturalness as being acquired in the course of first language acquisition, then dialects qualify as natural languages since dialects are transmitted from generation to generation by L1-acquisition-whereas standard languages do not (or at least only to a certain extent), because standard languages like the Germanic ones initially evolved as written languages which were secondarily learned by instruction and which were strongly influenced by extra-linguistic forces. On the basis of this L1 criterion Weiß (2001) distinguished between first- and second-order natural languages (N1 vs. N2 languages). So it seems natural to investigate dialect data, since L1-acquisition plays such an important role in generative linguistics (see Westergaard, this volume).

But it is not only the appropriateness concerning the data that makes the study of dialects important: a careful study of phenomena of the type mentioned above can also provide us with new theoretical insights in general. Consider again the Doubly filled Comp, illustrated above. Recently, this construction has been discussed in more detail in Bayer and Brandner (2008) and there it is shown that the occurrence of the complementizer is by no means 'optional' and thus a purely PF-phenomenon, but rather that typically a complementizer does not co-occur with short wh-words (of the type what, who, where) but that it is obligatory with complex wh-phrases, as exemplified above. An analysis was proposed that tries to capture this distribution by the assumption that these 'short' $w h$-words may be re-merged as heads into the structure and thus are complementizers and wh-elements simultaneously. This 'oscillation' between phrasal and head status of one and the same item turned out to be a natural consequence of recent conceptions of the phrase structure building component. Other cases where this dual status of $w h$-words seems to play a role are free relatives, as discussed in Donati (2006), and the lack of verb movement in whquestions in North-Norwegian dialects, Westergaard and Vangsnes (2005), Westergaard (this volume). So, a fine-grained analysis of apparently superficial variation between dialects and standardized languages and also an in-depth analysis of the dialectal phenomena can contribute to modern generative theorizing.

So the aim of the workshop was not only to provide an opportunity for the presentation of detailed analyses of dialectal phenomena. Additionally we wanted to discover and discuss new areas and phenomena where dialects can give us hints for some more fine-grained structure that is sometimes 'blurred' in the written languages. 
We hope that the papers in this issue will evoke further research and discussion in this area-either in that new data will come up and/or that the impact of these data on generative theorizing about the language faculty will be discussed on a broader empirical basis.

We would like to thank the organizers of the DGfS Jahrestagung in Siegen, all the authors and reviewers, special thanks to Benedikt Grimmler. Finally, of course, thanks to the editors of The Journal of Comparative Germanic Linguistics, Susi Wurmbrand and Henk van Riemsdijk.

\section{References}

Bayer, Josef, and Ellen Brandner. 2008. On wh-head movement and the doubly-filled-comp filter. In Proceedings of the 26th West Coast Conference on Formal Linguistics, eds. C.B. Chang and H.J. Haynie, 87-95. Somerville, MA: Cascadilla Press.

Donati, Catarina. 2006. On wh-head-movement. In Wh-movement: Move on, eds. L. Cheng, and N. Corver. Cambridge, MA: MIT Press.

Weiß, Helmut. 2001. On two types of natural languages. Some consequences for linguistics. Theoretical Linguistics 27(S): 87-103.

Westergaard, Marit R., and Øystein A. Vangsnes. 2005. Wh-questions, V2, and the left periphery of three Norwegian dialects. Journal of Comparative Germanic Linguistics 8: 117-158. 